\title{
Different patterns of cyclic AMP accumulation in rat corpora lutea after LH stimulation in vitro and in vivo
}

\author{
K. Ahrén, I. Khan and G. Selstam \\ Department of Physiology, University of Göteborg, Göteborg, Sweden
}

\begin{abstract}
Summary. Tissue levels of cyclic AMP were measured in rat corpora lutea at various times after administration of $\mathrm{LH}$ in vitro and in vivo. In-vitro addition of $\mathrm{LH}$ produced more pronounced accumulation of cyclic AMP in very young corpora lutea (1-day-old) than in the older corpora lutea (3-and 7-day-old). When LH was administered in vivo the highest accumulation of cyclic AMP was seen in the older corpora lutea (7- and 3-day-old).
\end{abstract}

\section{Introduction}

It now seems clear that the cyclic AMP (cAMP) system is involved in the stimulation by LH of steroidogenesis both in the ovary and in the testis (Marsh, 1975). Discrepancies exist, however, in many experimental systems between the amount of the trophic hormone required to stimulate steroid production, i.e. the sensitivity to the hormone, and that required to produce a detectable increase in cAMP levels in the gonad (Mendelson, Dufau \& Catt, 1975; Marsh, 1975). More information is therefore needed concerning changes of cAMP levels in the gonads under various experimental conditions.

The effect of LH on CAMP production by rat corpora lutea (CL) in vitro was first studied by Mason, Schaffer \& Toomey (1973) and Lamprecht, Zor, Tsafriri \& Lindner (1973), who found that the effect of LH on cAMP accumulation in CL of pregnant and pseudopregnant rats was markedly less than in simultaneously incubated ovaries of prepubertal rats. Mason et al. (1973) found no effect at all by $\mathrm{LH}$ in many of their experiments with $\mathrm{CL}$ of pregnant or pseudopregnant rats, particularly when older CL were used. A systematic study was then undertaken in this laboratory with isolated CL of different ages from PMSG-treated immature rats (Herlitz, Hamberger, Rosberg \& Ahrén, 1974). It was found that both $\mathrm{LH}$ and prostaglandin (PG) E-2 stimulated cAMP accumulation markedly and much more effectively when young (1-2-day-old) CL were used than when older (4-7-day-old) CL were used. A completely reversed pattern has since then been reported for the $\mathrm{LH}$ stimulation of adenylate cyclase in CL of different ages (Hunzicker-Dunn \& Birnbaumer, 1976) as well as for the development of LH receptors (Midgley, Zeleznik, Rajaniemi, Richards \& Reichert, 1974; Lee, Tateishi, Ryan \& Jiang, 1975). Hunzicker-Dunn \& Birnbaumer (1976) found a very marginal or no effect of LH on adenylate cyclase stimulation in isolated membranes of young CL (1-day-old) of pregnant or pseudopregnant rats and increased LH responsiveness with increasing age of the CL. Furthermore, binding experiments with ${ }^{125} \mathrm{I}$-labelled hCG have shown very few receptors in 1-2-day-old CL, but a marked increase in binding sites during the following days (Midgley et al., 1974; Lee et al., 1975).

In the present experiments the accumulation of cAMP in CL of different ages was measured after administration of $\mathrm{LH}$ in vivo. 


\section{Materials and Methods}

\section{Animals}

Immature female Sprague-Dawley rats were purchased from Anticimex Ltd, Stockholm, at 26 days of age, and kept in controlled environmental conditions (light 05:00-19:00 h). Food and water were always available.

\section{Induction of ovulation}

To obtain a well defined generation of CL, each rat was given a s.c. injection of 8 i.u. PMSG (Gestyl: NV Organon, The Netherlands) dissolved in 0.2 ml saline, between 08:00 and 10:00 h on Day 28 of life. This treatment has been shown to induce ovulation and subsequent formation of CL between 03:00 and 05:00 h of Day 31 (Herlitz, Koch, Khan \& Ahrén, 1976). The life span of these CL is 10-12 days. The CL were isolated between 10:00 and 13:00 h from 31-, 33- and 37-day-old rats and were designated as 1-, 3- and 7-day-old CL, respectively.

\section{Experimental procedure}

In-vitro experiments. The rats were killed by cervical dislocation and the ovaries were excised, dissected free from adhering fat and transferred to ice-chilled saline $(9 \mathrm{~g} \mathrm{NaCl} / \mathrm{l})$. The CL were isolated by dissection under a stereomicroscope; 3-5 CL were weighed on a torsion balance and transferred to flasks containing $1 \mathrm{ml} \mathrm{Krebs-Ringer-bicarbonate} \mathrm{buffer} \mathrm{(Umbreit,}$ Burris \& Stauffer, 1964) containing $1.25 \mathrm{~mm}$-calcium and $5.5 \mathrm{~mm}$-glucose, and preincubated for $30 \mathrm{~min}$ at $37^{\circ} \mathrm{C}$ under a gas phase of $95 \% \mathrm{O}_{2}$ and $5 \% \mathrm{CO}_{2}$. After preincubation, the $\mathrm{CL}$ were transferred to new incubation flasks with or without $\mathrm{LH}(\mathrm{NIH}-\mathrm{LH}-\mathrm{B} 9,10 \mu \mathrm{g} / \mathrm{ml})$, and the incubation was continued for various periods of time. At the end of incubation the $\mathrm{CL}$ were homogenized in $2 \mathrm{ml} 5 \%$ TCA and analysed as described later.

In-vivo experiments. The rats were anaesthetized with a single i.p. injection of pentobarbitone sodium (Mebumal: ACO), $4 \mathrm{mg} / 100 \mathrm{~g}$ body weight, dissolved in $0.5 \mathrm{ml}$ saline. $\mathrm{LH}$ (NIH-LH-S18, $5 \mu \mathrm{g} / \mathrm{rat}$ ) dissolved in $0.25 \mathrm{ml}$ saline was given i.v. into the tail vein. The ovaries were excised after various periods and transferred to ice-chilled saline. The CL were isolated and immediately frozen on solid $\mathrm{CO}_{2}$ and kept frozen until analysed for cAMP content.

\section{Analytical procedure}

After thawing, the CL were homogenized in $2 \mathrm{ml} 5 \%$ trichloroacetic acid. The protein content of the homogenate was determined as described by Lowry, Rosebrough, Farr \& Randall (1951), and the cAMP content was determined according to Gilman (1970), $\left[{ }^{3} \mathrm{H}\right] \mathrm{cAMP}$ was purchased from New England Nuclear, Boston, Massachusetts, U.S.A. All other chemicals (analytical grade) were purchased from Sigma Ltd or Merck Co.

\section{Phosphodiesterase determinations}

In a separate series of experiments CAMP-phosphodiesterase activity of CL was determined using basically the method described by Pöch (1971). In these experiments the rats were killed by cervical dislocation, and all CL from individual rats were homogenized in $2 \mathrm{ml} 100$ mM-Tris- $\mathrm{HCl}$. The homogenate was centrifuged at $2000 \mathrm{~g}$ for $15 \mathrm{~min}$. Albumin (final conc. $0.1 \%$ ) and $\left[{ }^{32} \mathrm{P}\right] \mathrm{cAMP}$ (final conc. 0.0125 or $12.5 \mu \mathrm{M}$ ) were added to aliquots of the supernatant. The enzyme reaction was carried out at $37^{\circ} \mathrm{C}$ for 5,10 and $15 \mathrm{~min}$ and terminated by the addition of $0.15 \mathrm{M}-\mathrm{ZnSO}_{4}$ and $0.15 \mathrm{M}-\mathrm{Ba}(\mathrm{OH})_{2}$. The samples were centrifuged and the supernatant counted for radioactivity. Enzyme activities were extrapolated to zero time (=initial velocity) by linear regression analysis. 


\section{Results}

The results of the in-vitro study show that LH had the most marked effect in the 1-day-old CL (Text-fig. 1). The patterns of cAMP accumulation also differed; in 7-day-old CL cAMP accumulation was still increasing at $120 \mathrm{~min}$, the longest time studied.

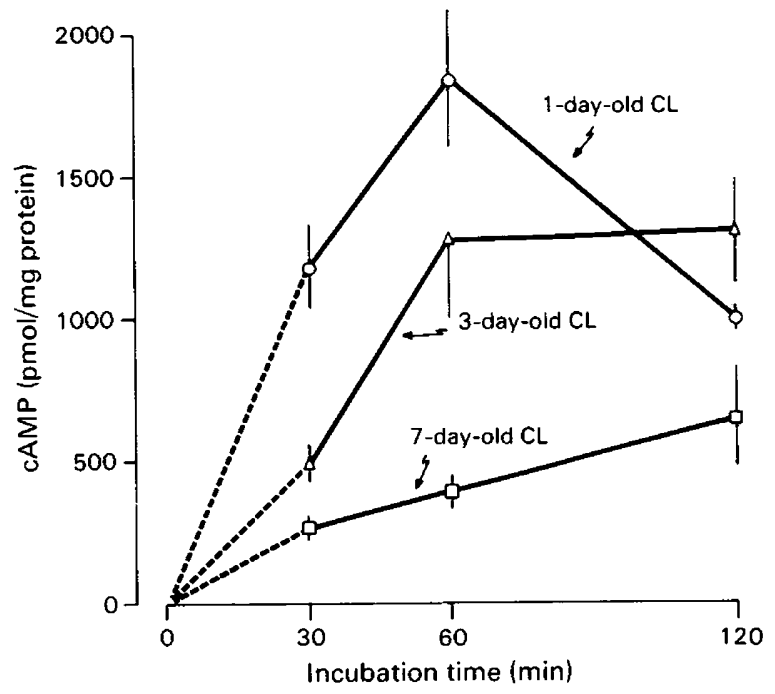

Text-fig. 1. Time course of the effect of LH on cAMP accumulation in vitro by 1-, 3- and 7-day-old CL. The figure shows mean \pm s.e.m. (5 observations/group) cAMP content in the tissue in presence of LH (LH-NIH-B9, $10 \mu \mathrm{g} / \mathrm{ml})$. Values for control CL incubated without $\mathrm{LH}$ (data not shown) were all low, varying between $25 \pm 6$ and $86 \pm 7 \mathrm{pmol} / \mathrm{mg}$ protein. Since no measurements were made in this particular experiment at the start of incubation (i.e. zero time) the first parts of the curves are shown with broken lines.

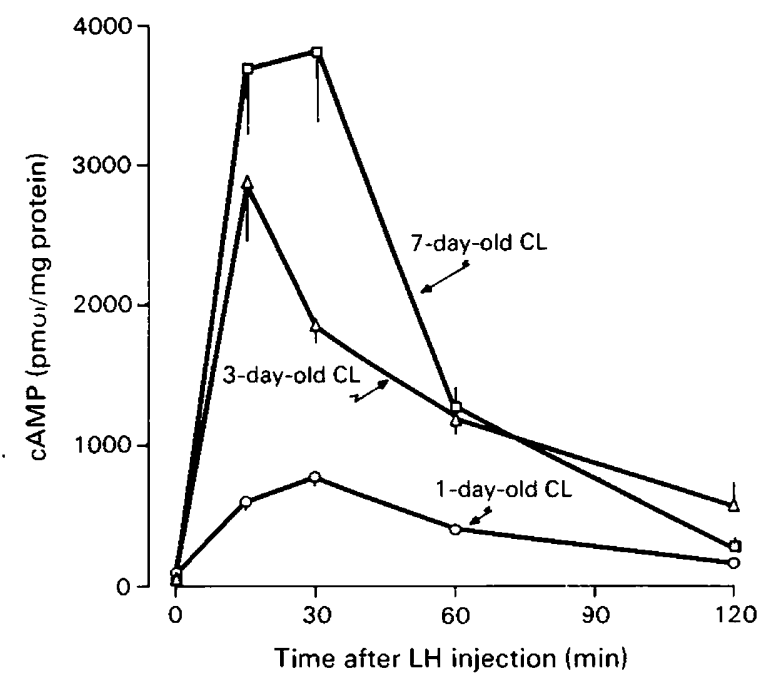

Text-fig. 2. Time course of the effect of LH on cAMP accumulation in vivo by 1-, 3- and 7-day-old CL. A single i.v. injection of LH (NIH-LH-S18, $5 \mu \mathrm{g} / \mathrm{rat}$ ) was given and CAMP was determined in the luteal tissue as described in 'Materials and Methods'. Values are mean \pm s.e.m. of $5-8$ observations per group. 
After LH injection in vivo, cAMP concentrations were highest in the 7-day-old CL for which the maximal values after hormonal stimulation were 4-5 times higher than that in the 1-day-old CL (Text-fig. 2). There were small differences in the pattern of CAMP accumulation between CL of different ages, but these differences were smaller than those obtained when the hormone was added in vitro.

Basal levels of cAMP in 1-, 3- and 7-day-old CL, i.e. the levels immediately after dissection from control rats, were $103 \pm 2 \cdot 5,42 \pm 4.4$ and $21 \pm 3 \mathrm{pmol} / \mathrm{mg}$ protein respectively. This small difference in basal levels of CAMP with the age of CL is in accordance with previous findings (Ahrén, Herlitz, Janson, Khan \& Rosberg, 1977).

No differences were seen in phosphodiesterase activities between corpora lutea of different ages (Table 1).

Table 1. Phosphodiesterase activities in rat corpora lutea of different ages

\begin{tabular}{cllll}
\hline \multirow{2}{*}{$\begin{array}{c}{ }^{32} \text { P CAMP conc. } \\
(\mu M)\end{array}$} & \multicolumn{4}{c}{ Phosphodiesterase activities (pmol/mg protein $\times$ min) } \\
\cline { 2 - 5 } & 2-day-old & 4-day-old & 6-day-old & 9-day-old \\
\hline $\begin{array}{c}0.0125 \\
12.5\end{array}$ & $6.42 \pm 0.50$ & $5.45 \pm 0.34$ & $6 \cdot 29 \pm 0 \cdot 16$ & $5 \cdot 62 \pm 0.29$ \\
& $1324 \pm 29$ & $1121 \pm 96$ & $1290 \pm 68$ & $1372 \pm 106$ \\
\hline
\end{tabular}

Values of initial velocities are given as mean \pm s.e.m. of 3 observations. No significant difference in phosphodiesterase activities was observed between the various ages of CL. Significances were tested with analysis of variance followed by Student-Newman-Keul's test.

\section{Discussion}

Our findings that the administration of LH in vivo has more marked effect on cAMP accumulation in 7-day-old and 3-day-old CL than in 1-day-old CL is consistent with the marked increase in LH receptors in older CL (Midgley et al., 1974; Lee et al., 1975) and the increased LH stimulation of adenylate cyclase in older CL (Hunzicker-Dunn \& Birnbaumer, 1976). In the present in-vivo experiments, however, there was also an effect in the 1-day-old CL with cAMP concentrations increasing from a basal level of $103 \pm 3$ to $768 \pm 49 \mathrm{pmol} / \mathrm{mg}$ protein by $30 \mathrm{~min}$. The magnitude of this increase seems surprisingly high in relation to the low receptor levels as well as low response of adenylate cyclase to $\mathrm{LH}$ reported in these young CL. Direct comparisons are, however, difficult, if not impossible at present, to make between hormone receptor levels and hormone stimulation of adenylate cyclase activity on the one hand and hormone-stimulated cAMP accumulation in the intact tissue on the other.

The pattern of the in-vitro effect of LH on CAMP accumulation in CL of different ages was basically the same as that reported by Herlitz et al. (1974), i.e. the most marked response was in the young CL (1- and 3-day-old). A drastic difference therefore exists not only in relation to the above-mentioned studies on receptor development and LH-stimulated adenylate cyclase but also in relation to the in-vivo effect on cAMP accumulation. The reason for this clear difference in pattern between the in-vivo and in-vitro effect of LH on cAMP accumulation in CL of different ages is not clear, but several possibilities exist and must be experimentally tested. One possibility to explain the small effect of LH in vitro on the older CL is that phosphodiesterase activity might be more active in older than in younger $\mathrm{CL}$ and that phosphodiesterase activity might be more important for the accumulation of cAMP under in-vitro than under in-vivo conditions. There are, in fact, studies on bovine corpora lutea indicating higher phosphodiesterase activity in older than in younger CL collected during various phases of the oestrous cycle (Stansfield, Horne \& 
Wilkinson, 1971). A preliminary study in this laboratory also indicated slightly increasing phosphodiesterase activity with increasing CL age in pseudopregnant rats (Khan, Rosberg, Herlitz \& Ahrén, 1975). The more detailed analysis performed in the present study could not however, reveal any difference in phosphodiesterase activity between younger and older CL. It seems unlikely, therefore, that changes in phosphodiesterase activity can explain the marked difference in the pattern of cAMP accumulation in CL of different ages after LH administration in vivo and in vitro. Another possibility, more attractive in our opinion, is that the difference is related to the localization of the receptor development in the newly formed CL. Autoradiographic studies by Rajaniemi, Midgley, Duncan \& Reichert (1977) have shown that the granulosa cells of the newly formed CL (i.e. a few hours after ovulation) become labelled only peripherally, when the animals are injected with ${ }^{125}$ I-labelled $\mathrm{hCG}$, but that the labelling increases centripetally when rats with 2-3-day-old CL are used. This receptor development towards the central part of the CL parallels an increase in weight and total protein content of the CL (Herlitz et al., 1974). It might therefore be that the newly formed CL offers the most suitable and optimal in-vitro conditions for LH to reach and bind to its receptors when the whole CL is studied, as in the present study, with less suitable conditions in the older CL. The conditions might be just the reverse in vivo, when the hormone reaches the cells via the circulation, with very few vessels to the peripheral granulosa cells during the first hours after ovulation and then development of a dense capillary network in the mature functional CL (Bassett, 1943). Niswender, Reimers, Diekman \& Nett (1976) have suggested a relationship between local CL blood flow and ${ }^{125} \mathrm{I}$-labelled hCG binding under various experimental conditions in the ovary from ewes induced to superovulate.

A third possibility which cannot be entirely excluded is that the small effect of $\mathrm{LH}$ in vitro on the older CL might be a consequence of the mere increase in size and morphological change in structure of CL with development. The newly formed CL in our PMSG-treated rats has a weight of about $0.4 \mathrm{mg}$ while the 6-7-day-old CL has a weight of about $1.2 \mathrm{mg}$ (Herlitz et al., 1974). The structure is also more compact in the mature CL than in the newly formed CL (Bassett, 1943). It might therefore be that penetration of substances (substrates, $\mathrm{O}_{2}, \mathrm{LH}$ ) from the incubation medium to the central parts of the CL is less effective in the older CL.

One special aspect has to be taken into consideration when interpreting the accumulation of cAMP in a tissue after hormonal stimulation, namely the possibility of release to the incubation medium or the blood stream during the experiment. In-vitro studies with various compartments of the rat ovary demonstrated a relatively low release of cAMP from isolated CL (Herlitz et al., 1974) in comparison to isolated prepubertal ovaries (Selstam et al., 1976) and isolated follicles (Nilsson, Rosberg \& Ahren, 1974). The release of cAMP in vivo to the ovarian venous blood after LH stimulation has only been studied with the follicular-phase rabbit ovary (Selstam, Janson \& Edén, 1976). It is, however, possible that the very young CL, which has been reported to have dilated and leaky capillaries (Bassett, 1943), releases considerable amounts of cAMP to the blood'stream, resulting in low accumulation in the tissue compared to events in vitro.

Further studies are necessary to establish if any of the above mentioned possibilities can explain the difference seen in the present experiment between the effects of LH in vivo and in vitro. This difference has, however, to be taken into consideration when evaluating future experiments with CL in vitro.

We thank Miss Barbro Henskog for expert technical assistance; chem. eng. Sten Rosberg for constructive criticism and valuable advice; Mrs Gun Derevall and Mrs Britt-Marie Helder for typing the manuscript; NIH for hormones; and the Swedish Medical Research Council (14X-27); Leo Ltd, Research Foundation, Helsingborg (76.001); Svenska Sällskapet för Medicinsk Forskning, Magnus Bergvall's Foundation and the Medical Faculty, University of Göteborg, for financial support. 


\section{References}

Ahrén, K., Herlitz, H., Janson, P.O., Khan, M.I. \& Rosberg, S. (1977) Control of luteal function. In Endocrinology, Vol. 1, pp. 324-329. Ed. V. H. T. James. Excerpta Medica (Int. Congr. Ser. No. 402), Amsterdam.

Bassett, D.L. (1943) The changes in the vascular pattern of the ovary of the albino rat during the estrous cycle. Am. J. Anat. 73, 251-280.

Gilman, A.G. (1970) A protein binding assay for adenosine 3:5-cyclic monophosphate. Proc. natn. Acad. Sci. U.S.A. 67, 305-312.

Herlitz, H., Hamberger, L., Rosberg, S. \& Ahrén, K. (1974) Cyclic AMP in isolated corpora lutea of the rat: influence of gonadotrophins and prostaglandins. Acta endocr., Copenh. 77, 737-752.

Herlitz, H., Koch, Y., Khan, M.I. \& Ahrén, K. (1976) Effect of follicle-stimulating hormone on cyclic AMP levels in young corpora lutea of the rat. Eur. J. Obstet. Gynec. Reprod. Biol. 6/4, 175-179.

Hunzicker-Dunn, M. \& Birnbaumer, L. (1976) Adenylyl cyclase activities in ovarian tissues. III. Regulation of responsiveness to $\mathrm{LH}, \mathrm{FSH}$, and $\mathrm{PGE}_{1}$ in the prepubertal, cycling, pregnant, and pseudopregnant rat. Endocrinology 99, 198-210.

Khan, 1., Rosberg, S., Herlitz, H. \& Ahrén, K. (1975) Cyclic AMP content and phosphodiesterase activity in rat corpora lutea of different ages. Acta physiol. scand. 95, Suppl. 53 A.

Lamprecht, S.A., Zor, U., Tsafriri, A. \& Lindner, H.R. (1973) Action of prostaglandin $E_{2}$ and of luteinizing hormone on ovarian adenylate cyclase, protein kinase and ornithine decarboxylase activity during postnatal development and maturity in the rat. $J$. Endocr. 57, 217-233.

Lee, C.Y., Tateishi, K., Ryan, R.J. \& Jiang, N.S. (1975) Binding of human chorionic gonadotropin by rat ovarian slices: dependence on the functional state of the ovary. Proc. Soc. exp. Biol. Med. 148, 505-507.

Lowry, O.H., Rosebrough, N.J., Farr, A.L. \& Randall, R.J. (1951) Protein measurement with the folin phenol reagent. J. biol. Chem. 193, 265-275.

Marsh, J.M. (1975) The role of cyclic AMP in gonadal function. Adv. cyclic Nucleotide Res. 6, 137-199.

Mason, N.R., Schaffer, R.J. \& Toomey, R.E. (1973) Stimulation of cyclic AMP accumulation in rat ovaries in vitro. Endocrinology 93, 34-41.
Mendelson, C., Dufau, M. \& Catt, K. (1975) Gonadotropin binding and stimulation of cyclic adenosine $3^{\prime}: 5^{\prime}$-monophosphate and testosterone production in isolated Leydig cells. J. biol. Chem. 250, 8818-8823.

Midgley, A.R., Jr, Zeleznik, A.J., Rajaniemi, H.J., Richards, J.S. \& Reichert, L.E., Jr (1974) Gonadotropin-receptor activity and granulosa-luteal cell differentiation. In Gonadotropins and Gonadal Function, pp. 416-429. Ed. N. R. Moudgal. Academic Press, New York.

Nilsson, L., Rosberg, S. \& Ahrén, K. (1974) Characteristics of the cyclic $3^{\prime}, 5^{\prime}$-AMP formation in isolated ovarian follicles from PMSG-treated immature rats after stimulation in vitro with gonadotrophins and prostaglandins. Acta endocr., Copenh. 77, 559-574.

Niswender, G.D., Reimers, T.J., Diekman, M.A. \& Nett, T.M. (1976) Blood flow: A mediator of ovarian function. Biol. Reprod. 14, 64-81.

Pöch, G. (1971) Assay of phosphodiesterase with radioactively labelled cyclic $3^{\prime}, 5^{\prime}$-AMP as substrate. Naunyn-Schmiedebergs Arch. Pharmak. 268, 272299.

Rajaniemi, H.J., Midgley, A.R., Jr, Duncan, J.A. \& Reichert, L.E., Jr (1977) Gonadotropin receptors in rat ovarian tissue: III. Binding sites for luteinizing hormone and differentation of granulosa cells to luteal cells. Endocrinology 101, 898-910.

Selstam, G., Janson, P.O. \& Edén, S. (1976) Effect of LH on the release of cyclic AMP by the rabbit ovary perfused in vivo and in vitro. J. Reprod. Fert. 46, 355-358.

Selstam, G., Rosberg, S., Liljekvist, J., Grönquist, L., Perklev, T. \& Ahrén, K. (1976) Differences in action of LH and FSH on the formation of cyclic AMP in the prepubertal rat ovary. Acta endocr., Copenh. 81, $150-164$.

Stansfield, D.A., Horne, J.R. \& Wilkinson, G.H. (1971) Adenosine 3',5'-cyclic phosphate phosphodiesterase of corpus luteum. Biochim. Biophys. Acta 227, 413-418.

Umbreit, W.W., Burris, R.H. \& Stauffer, J.F. (1964) Manometric Techniques. 4th edn, pp. 132-133. Burgess, Minneapolis. 